\title{
Biosorben Daun Ketapang dengan Pengaktifan Asam Sitrat sebagai Pereduksi Merkuri
}

\author{
Biosorbent of Ketapang Leaf with Activation of Citric Acid as Mercury Reduction \\ Muhammad Aulia Fadhil ${ }^{1}$, Fariz Maulana Akbar ${ }^{1}$, Annissa Millenia Ramadhani', \\ Yuli Ristianingsih ${ }^{3}$, Isna Syauqiah ${ }^{1}$ \\ ${ }^{1}$ Jurusan Teknik Kimia, Universitas Lambung Mangkurat, Jl. A. Yani Km 36 Kota \\ Banjarbaru, Kalimantan Selatan, 70714, Indonesia \\ ${ }^{2}$ Jurusan Agroekoteknologi, Universitas Lambung Mangkurat, Jl. A. Yani Km 36 Kota \\ Banjarbaru, Kalimantan Selatan, 70714, Indonesia \\ ${ }^{3}$ Jurusan Teknik Kimia, UPN Veteran Yogyakarta, Jl. SWK 104 (Lingkar Utara) \\ Condong Catur, Yogyakarta, 55283, Indonesia \\ Email: mafadhil15@gmail.com
}

Naskah diterima: 4 Juli 2019; Naskah disetujui: 1 Agustus 2019

\begin{abstract}
South Kalimantan has a gold mining industry that produces waste that can pollute the environment and is harmful to public health. One of the hazardous contaminants contained in the gold mining industry is mercury. This study aims to make biosorbent of ketapang leaves which will be used to reduce mercury content in gold mining waste.. The study began with washing the ketapang leaves to remove the impurities and then dried 34 days under the sun to reduce the water content. The next step is a simple carbonization process by using furnaces at a temperature of $300{ }^{\circ} \mathrm{C}$ for 30 minutes as the optimum operating condition so that activated carbon is formed called BDK. In the final stage, the biosorbent of ketapang leaves with $0.1 \mathrm{~N}$ citric acid was activated to produce biosorbent of ketapang leaves called BDK-COOH. The test results were carried out by SEM and FTIR analysis. The results of SEM analysis showed biosorbents that form large and large pores caused by carbonization and activation processes. Likewise, the results of FTIR analysis formed an active functional group to absorb heavy metals in terms of shifting absorption bands shown by FTIR. Based on analysis known that ketapang leaves can be used to reduce mercury waste in gold mining.
\end{abstract}

Keywords: adsorption, biosorbent, ketapang leaves, mercury

\begin{abstract}
ABSTRAK
Kalimantan Selatan memiliki industri penambangan emas yang menghasilkan limbah yang dapat mencemari lingkungan dan berbahaya bagi kesehatan masyarakat. Salah satu kontaminan berbahaya yang terkandung dalam industri penambangan emas adalah merkuri. Penelitian ini bertujuan untuk membuat biosorben daun ketapang yang akan digunakan untuk mereduksi kandungan merkuri pada limbah penambangan emas. Penelitian dimulai dengan pencucian daun ketapang untuk menghilangkan pengotornya lalu dijemur 3-4 hari untuk mengurangi kandungan air. Langkah selanjutnya adalah proses karbonisasi sederhana dengan menggunakan furnace pada suhu $300^{\circ} \mathrm{C}$ selama 30 menit sebagai kondisi operasi optimumnya sehingga terbentuk karbon aktif yang disebut BDK. Pada tahap akhir dilakukan pengaktifan biosorben daun ketapang dengan asam
\end{abstract}


sitrat 0,1 $\mathrm{N}$ menghasilkan biosorben daun ketapang yang disebut BDK-COOH. Hasil pengujian dilakukan dengan analisis SEM dan FTIR. Hasil analisis SEM menunjukkan biosorben yang terbentuk pori kecil dan semakin banyak yang diakibatkan proses karbonisasi dan aktifasi. Begitu pula hasil analisis FTIR terbentuk gugus fungsional yang aktif untuk menyerap logam berat ditinjau dari pergeseran pita serapan yang ditunjukkan FTIR. Berdasarkan hasil analisis tersebut dapat diketahui bahwa daun ketapang bisa digunakan untuk mereduksi limbah merkuri pada penambangan emas.

Kata Kunci: adsorpsi, biosorben, daun ketapang, merkuri

\section{PENDAHULUAN}

Tercemarnya lingkungan yang diakibatkan oleh logam berat sudah menjadi permasalahan lingkungan yang sangat disoroti. Pencemaran ini dapat menimbulkan berbagai gangguan kesehatan maupun ekosistem lingkungan bahkan dapat mengakibatkan kematian (Wicakso dkk, 2012). Logam berat sering kali merupakan bahan yang tidak bisa diuraikan oleh organisme sehingga hanya terakumulasi di lingkungan, salah satunya pada ekosistem perairan logam berat memungkinkan membentuk senyawa kompleks secara adsorbsi maupun kombinasi dengan bahan organik dan anorganik yang terdapat di ekosistem tersebut (Wicakso dkk, 2012). Salah satu logam berat yang tidak bisa diuraikan oleh organisme hidup di dalam ekosistem lingkungan adalah merkuri.

Logam berat merkuri sering dijumpai pada kandungan limbah sisa penambangan emas yang mana merkuri sendiri digunakan untuk mengikat dan memurnikan kandungan emas. Sehingga sudah dipastikan air sungai maupun laut di daerah penambangan emas akan terkontaminasi merkuri. Kandungan logam berat pada limbah penambangan emas dapat dilihat pada Tabel 1 sebagai berikut (Agus dkk, 2005):

Tabel 1. Kandungan Logam Berat pada Limbah Penambangan Emas

\begin{tabular}{ccc}
\hline Logam berat & $\begin{array}{c}\text { Kadar } \\
(\mathbf{p p m})\end{array}$ & $\begin{array}{c}\text { Kepmen LH No. 51 Tahun 2004 } \\
(\mathbf{p p m})\end{array}$ \\
\hline $\mathrm{Hg}$ & 0,086 & 0,001 \\
$\mathrm{~Pb}$ & 4,086 & 0,03 \\
$\mathrm{Cu}$ & 0,212 & 0,02 \\
\hline
\end{tabular}

Banyak metode telah dikembangkan untuk mengurangi kandungan merkuri yang telah terakumulasi di ekosistem perairan, salah satunya adalah metode adsorpsi dengan memanfaatkan biomassa. biomassa yang mampu menyerap secara pasif dan/atau terjadi kompleksasi ion logam disebut biosorben. 
Biomassa alami menjadi alternatif yang seringkali dimanfaatkan sebagai pereduksi logam berat berbahaya yang terkandung dalam suatu limbah industri khususnya limbah cair (Mack, 2007). Biosorpsi berlangsung cepat dalam proses penyerapan ion logam sehingga seringkali dapat dibandingkan dengan kinerja mikroorganisme untuk menyerap logam berat yang terkandung dalam limbah (Erriek, 2012). Faktor yang mempengaruhi kinerja biosorben untuk mencapai kemampuan optimumnya, antara lain $\mathrm{pH}$, waktu kontak dan suhu (Erriek, 2012). Adapun beberapa penelitian yang telah dilakukan dengan memanfaatkan biomassa untuk mereduksi logam berat dapat dilihat pada Tabel 2 sebagai berikut.

Tabel 2. Pemanfaatan Biomassa untuk Mereduksi Logam Berat

\begin{tabular}{lccc}
\hline \multicolumn{1}{c}{ Peneliti } & Biomassa & Logam berat & Efisiensi Penyerapan \\
\hline (Irawan, 2014) & Serat purun tikus & $\mathrm{Hg}$ & $65 \%$ \\
(Wardalia, 2016) & Sekam padi & $\mathrm{Pb}$ & $99 \%$ \\
(Ningsih, 2016) & Tongkol jagung & $\mathrm{Pb}$ & $94,7 \%$ \\
(Hayati, 2018) & Biji trembesi & $\mathrm{Cr}$ & $82,7 \%$ \\
\hline
\end{tabular}

Daun ketapang juga seringkali diekstrak untuk diambil senyawa fenoliknya yang mampu mereduksi logam berat (Rusnaenah, 2017). Daya ikat terhadap logam berat yang tinggi dikarenakan kandungan unsur karbon pada daun ketapang relatif tinggi (Islamiah, 2016). Daun ketapang mengandung unsur $C(60,28 \%)$ dan $O(30,67 \%)$ penyusun utamanya (Mulyawan, 2015). Daunnya memiliki ciri berwarna hijau tua mengkilap dengan ujungnya berbentuk bulat tumpul dengan tekstur kasar dan ketika daun jatuh warnanya akan berubah menjadi merah yang dikarenakan mempunyai aktivasi anti bakteri di dalamnya (Alfiany, 2013). Dengan kandungan unsur C yang relatif tinggi tersebut dan juga ketersediaan yang melimpah membuat daun ketapang sangat berpotensi untuk dimanfaatkan sebagai biosorben untuk mereduksi merkuri pada limbah penambangan emas.

\section{METODOLOGI PENELITIAN}

Penelitian ini dilakukan dengan dua perlakuan, yaitu (1) preparasi biosorben daun ketapang tanpa modifikasi dan (2) preparasi biosorben daun ketapang dengan asam sitrat yang dilakukan di Laboratorium Teknologi Proses Program Studi S-1 Teknik Kimia Fakultas Teknik Universitas Lambung Mangkurat. Alat-alat yang dipakai adalah gelas 
beker, gelas ukur, labu ukur, gelas arloji, cawan porselin, erlenmeyer, sudip, penjepit, neraca analitik, pipet, thermo scientific Cimarec stirring hot plate, Neycraft manual control fiber furnace, Memmert UN 55 plus universal oven, desikator 200 dengan plat porselain Normax, coffee grinder Aicok, universal test pH paper dan ayakan 200 mesh. Bahan yang dipakai adalah daun ketapang, air demin, kertas saring dan asam sitrat $\left(\mathrm{C}_{6} \mathrm{H}_{8} \mathrm{O}_{7}\right)$.

\section{Preparasi Biosorben Daun Ketapang}

\section{(a) Pembuatan Biosorben Daun Ketapang tanpa Modifikasi}

Tahap pertama yang dilakukan adalah pencucian daun ketapang dari kotoran yang menempel, kemudian dikeringkan menggunakan sinar matahari selama 3 hari. Setelah kering daun ketapang dibakar dengan furnace suhu $300{ }^{\circ} \mathrm{C}$ selama 30 menit. Daun ketapang yang telah dikarbonisasi dihaluskan dengan blender dan diayak dengan ukuran 200 mesh untuk mendapatkan biosorben daun ketapang atau yang disebut BDK. Kemudian dilakukan uji Scanning electron microscope (SEM) dan Fourier Transmitance Infra-Red (FTIR) pada BDK tersebut.

\section{(b) Preparasi Biosorben Daun Ketapang dengan Asam Sitrat}

Serbuk daun ketapang yang diperoleh dari tahap (a) selanjutnya direndam menggunakan larutan asam sitrat 0,1 M. Perendaman dilakukan dengan cara memasukkan $10 \%(\mathrm{~b} / \mathrm{v})$ ke dalam larutan asam sitrat $0,1 \mathrm{M}$, kemudian larutan tersebut di-stirrer dengan kecepatan 100 rpm selama 2 jam. Setelah itu larutan disaring untuk mendapatkan serbuk daun ketapang. Setelah itu serbuk daun ketapang dikeringkan dalam oven selama 2 jam pada suhu $100^{\circ} \mathrm{C}$. Kemudian serbuk daun ketapang dicuci dengan air demin hingga mempunyai $\mathrm{pH}$ yang netral. Setelah itu serbuk daun ketapang kembali dioven pada suhu $80^{\circ} \mathrm{C}$ selama 2 jam. Kemudian dilakukan uji Scanning electron microscope (SEM) dan Fourier Transmitance Infra-Red (FTIR) pada biosorben daun ketapang. Selanjutnya biosorben daun ketapang ini dinamakan BDK-COOH.

\section{Karakterisasi}

Sampel yang sudah diberikan perlakuan hingga menjadi biosorben dikarakterisasi dengan alat scanning electron microscope (SEM) Jeol JSM 6510 LA pada perbesaran 500-10000 kali untuk mengetahui morfologi permukaan sampel. Karakterisasi dengan alat four transmitance infra-red (FTIR) Parkin Elmer Spektrum2 dilakukan untuk mengetahui gugus fungsional. 


\section{HASIL DAN PEMBAHASAN}

Pemanfaatan daun ketapang sebagai biosorben dalam penelitian ini dikarenakan pemanfaatan daun ketapang yang sangat kurang berbanding terbalik dengan ketersediaan daun ketapang itu sendiri sehingga membuat daun ini hanya menjadi limbah lingkungan. Selain itu juga, pengaplikasian sebagai biosorben ini juga relatif sederhana tanpa membutuhkan instrumentasi yang rumit (Mulyawan dkk, 2015). Karakterisasi SEM dan FTIR dilakukan untuk mengetahui potensi gugus aktif yang dapat menjadi penjerap logam berat salah satunya merkuri.

\section{Scanning Electron Microscope (SEM)}

Karakterisasi dengan SEM dilakukan untuk mengetahui morfologi permukaan dan ukuran pori biosorben sebelum dikarbonisasi, sesudah dikarbonisasi dan diaktifkan. Dari pengujian dengan SEM, didapati hasil berupa gambar yang dipengaruhi oleh unsur penyusunnya. Daun ketapang mengandung unsur C $(60,28 \%)$ dan O $(30,67 \%)$ penyusun utamanya (Mulyawan, 2015). Gambar 1, 2 dan 3 merupakan hasil analisis SEM pada daun ketapang sebelum karbonisasi, setelah karbonisasi dan setelah diaktifkan dengan larutan asam sitrat $0,1 \mathrm{~N}$ :

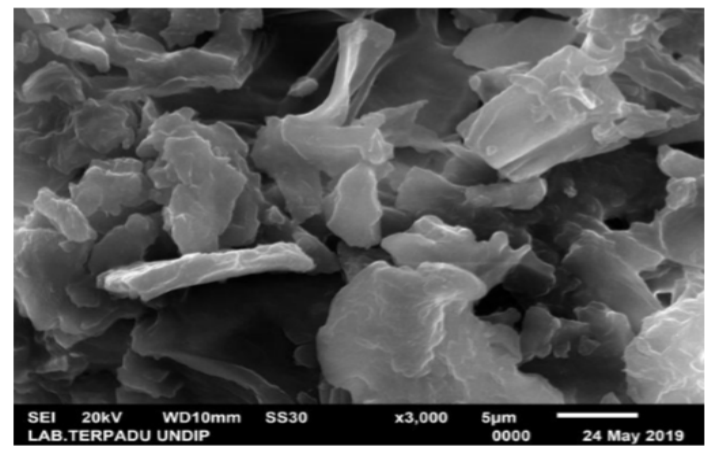

Gambar 1. Daun Ketapang Sebelum Karbonisasi

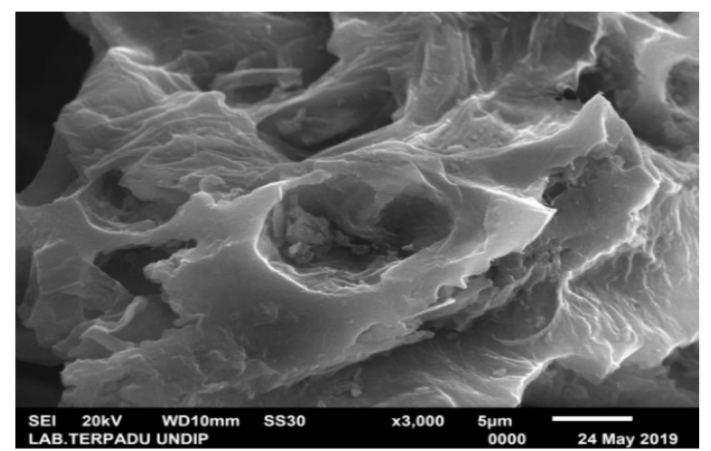

Gambar 2. Daun Ketapang Setelah Karbonisasi 


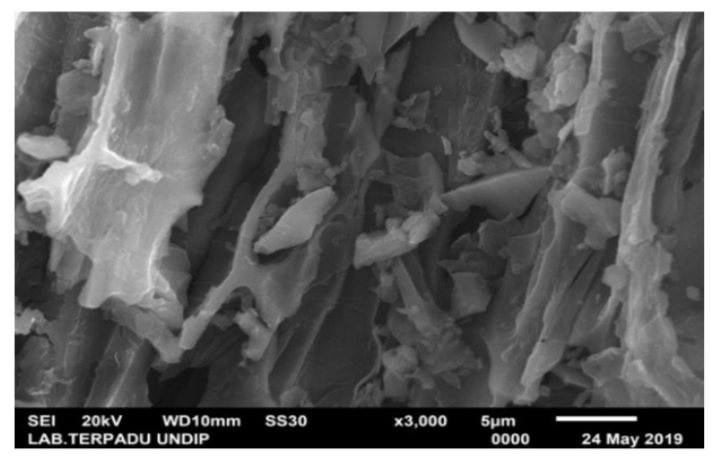

Gambar 3. Daun Ketapang dengan Pengaktifan Larutan Asam Sitrat 0,1 N

Berdasarkan hasil analisis SEM dapat dilihat bahwa jumlah pori yang terbentuk semakin banyak karena pengaruh perlakuan terhadap daun ketapang. Semakin banyak pori yang terbentuk pada permukaan daun ketapang maka biosorben menjadi semakin baik, hal ini dikarenakan luas serapan dari biosorben semakin besar sehingga memungkinkan proses adsorpsi lebih maksimal. Selain itu juga, ukuran partikel adsorben dibuat kecil bertujuan untuk memperbesar luas bidang kontak antara biosorben dengan aktivator maupun limbah menjadi lebih mudah. Hal ini juga diperkuat oleh Hayati (2016) bahwa pemberian perlakuan pada adsorben akan membuat kinerja penyerapan dari adsorben semakin baik terhadap logam berat.

\section{Fourier Transmitance Infra-Red (FTIR)}

Karakterisasi dengan FTIR dilakukan untuk mengetahui gugus fungsi yang terdapat pada biomassa. Analisis FTIR akan memperlihatkan gugus fungsi dari biomassa berupa hasil pita serapan. Gambar 4 merupakan hasil analisis FTIR pada daun ketapang sebelum karbonisasi, setelah karbonisasi dan setelah diaktifkan dengan larutan asam sitrat $0,1 \mathrm{~N}$ :

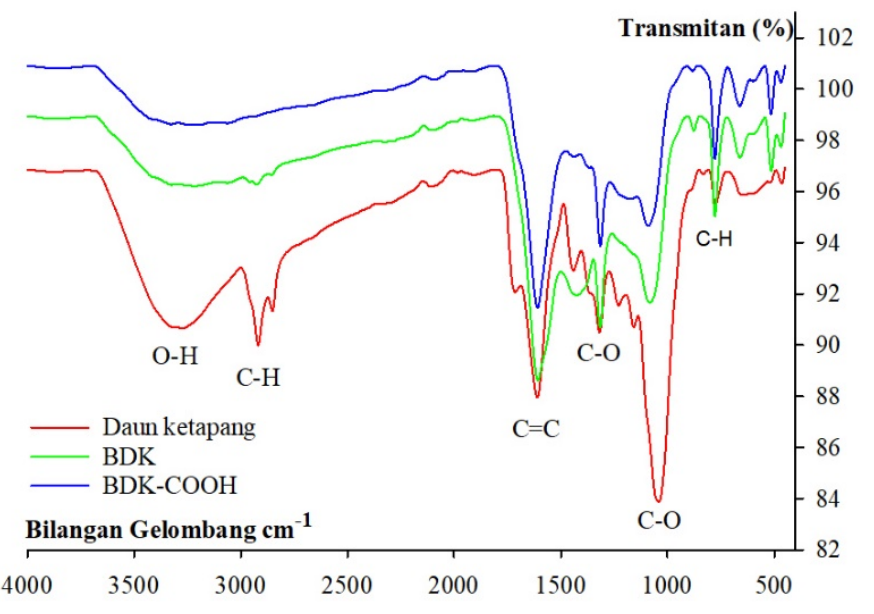

Gambar 4. Hasil Analisis FTIR 
Berdasarkan Gambar 4 pada hasil analisis FTIR daun ketapang dapat dilihat bahwa pita serapan $1610 \mathrm{~cm}^{-1}$ merupakan uluran C-O karboksil yang diperkuat dengan pita serapan $1318 \mathrm{~cm}^{-1}$ dan gugus alkohol primer $(\mathrm{C}-\mathrm{OH})$ pada pita serapan $1040 \mathrm{~cm}^{-1}$. Setelah diberikan perlakuan dengan karbonisasi dan pengaktifan terjadi pergeseran pita serapan yang dapat dilihat pada Gambar 4. Analisis FTIR memperlihatkan uluran gugus -OH alkohol pada pita serapan $3216 \mathrm{~cm}^{-1}$ hingga $3225 \mathrm{~cm}^{-1}$, gugus uluran C-O karboksilat pada pita serapan $1607 \mathrm{~cm}^{-1}$ hingga $1609 \mathrm{~cm}^{-1}$ dan juga gugus alkohol primer (C-OH)

pada pita serapan $1083 \mathrm{~cm}^{-1}$ hingga $1092 \mathrm{~cm}^{-1}$. Pita serapan yang dihasilkan dari analisis FTIR juga menunjukkan setelah pengaktifan dengan asam sitrat $0,1 \mathrm{~N}$ terlihat terbentuk gugus karboksil -COOH pada pita serapan $1092 \mathrm{~cm}^{-1}$ hingga $1610 \mathrm{~cm}^{-1}$.

Pergeseran pita serapan berkisar $10-20 \mathrm{~cm}^{-1}$ pada masing-masing sampel dikarenakan terjadi perubahan gugus fungsi yang diakibatkan perlakuan yang diberikan pada sampel seperti karbonisasi dan pengaktifan dengan asam sitrat 0,1 $\mathrm{N}$ maupun kontak dengan limbah. Hal ini juga dikuatkan dengan penelitian sebelumnya yang dilakukan oleh (Mulyawan, 2015) tentang adsorben yang mengikat limbah logam timbal membuat pita serapan menjadi bergeser hingga $10 \mathrm{~cm}^{-1}$. Selain itu juga, Mawardi (2007) juga mengemukakan hal yang sama pergeseran pita serapan terjadi akibat dari perlakuan yang diberikan pada biomassa.

\section{KESIMPULAN}

Pemberian perlakuan pada pembuatan biosorben daun ketapang membuat adsorpsi dari biosorben semakin baik. Karbonisasi pada suhu $300{ }^{\circ} \mathrm{C}$ dan pengaktifan dengan asam sitrat 0,1 $\mathrm{N}$ memperbesar luas permukaan bidang kontak antara adsorben dengan adsorbat sehingga daya serap adsorben terhadap logam $\mathrm{Hg}$ pun semakin tinggi.

\section{UCAPAN TERIMA KASIH}

Terima kasih diucapkan kepada KEMENRISTEK DIKTI atas pendanaan hibah PKM-P dan Universitas Lambung Mangkurat sebagai sumber dana utama dalam melaksanakan penelitian ini. 


\section{DAFTAR PUSTAKA}

Agus, C. S. and Sukandarrumidi W. (2005) 'Dampak Limbah Cair Hasil Pengolahan Emas Terhadap Kualitas Air Sungai Dan Cara Mengurangi Dampak dengan Menggunakan Zeolit (the Impact of Liquid Waste of Gold Processing in the River Water Quality and the Method for Minimizing the Impact by Using Zeolite)', Jurnal Manusia dan Lingkungan, 12, 13-19.

Alfiany, H., S. Bahri and Nurakhirawati (2013) 'Kajian Penggunaan Arang Aktif Tongkol Jagung Sebagai Adsorben Logam Pb dengan Beberapa Aktivator Asam', Jurnal Natural Science, 2, 11.

Erriek A. (2012) 'Biosorpsi Logam Cu (ii) dan Cr (VI) pada Limbah Elektroplating dengan Menggunakan Bimassa Phanerochaete Chrysosporium', Jurnal Teknik Kimia, 4.

Hayati, G. I. P., Bunga R. and Yuli R. (2018) 'Pengaruh Variasi Konsentrasi Adsorben Biji Trembesi terhadap Penurunan Kadar Logam Kromium (Cr) Total pada Limbah Industri Sasirangan', Jurnal Konversi, 5, 1-4.

Irawan, C., Ardiansyah and Naisha H. (2014) 'Potensi Hayati Serat Purun Tikus (Eleocharis Dulcis) dalam Proses Adsorpsi Kandunan Logam Berat Merkuri (Hg), TSS dan COD pada Limbah Cair Pertambangan Emas', Jurnal Konversi, 3, 17-24.

Islamiah, I. U., Umroh P. and Eva (2016) 'Ability of ketapang leaf (Terminalia cattapa) in reducing the content of heavy metals copper $(\mathrm{Cu})$ in the water', Journal of Aquatropica Asia, 2.

Mack, C., Wilhelmi B., Duncan J. R. and Burgess J. E. (2007) 'Biosorption of Precious Metals', Biotech. Adv., 25, 7.

Mulyawan, R., Asep S. and Foliatini (2015) 'Biosorpsi Timbal Oleh Biomassa Daun Ketapang. Molekul, 10, 12.

Ningsih, D. (2016) 'Adsorpsi Logam Timbal (Pb) dari Larutannya dengan Menggunakan Adsorben dari Tongkol Jagung', Akademika Kimia, 5, 55-60.

Rusnaenah, A. Z., Muhammad Budi and Prastawa (2017) 'Biosynthesis of Silver Nanoparticles Using Ketapang Leaf Extract, Modification With p-Coumaric Acid For Detecting Melamine', Ind. J. Chem. Res, 4, 367-372.

Wardalia (2016) 'Karakterisasi Pembuatan Adsorben dari Sekam Padi Sebagai Pengadsorp Logam Timbal pada Limbah Cair', Integrasi Proses, 6, 83-88. 